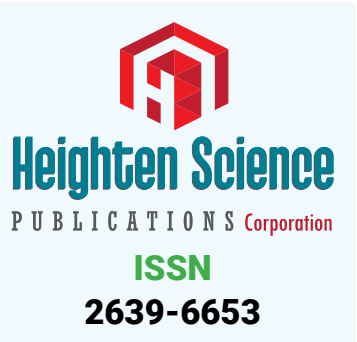

*Address for Correspondence: Dr. Farahnaz Fallahian, Pulmonology and critical care Fellow, Rasoul Akram Hospital, Iran, University of Medical Sciences, Tehran, Iran, Email: falahianfff@yahoo.com

Dr. Seyed MohammadReza Hashemian, Associate Professor, Chronic Respiratory Disease Research Center (CRDRC), National Research Institute of Tuberculosis and Lung Disease (NRITLD), Shahid Beheshti University of Medical Sciences (SBMU), Masih Daneshvari Hospital, Darabad St., Tehran, Iran, Tel/Fax: +98 9121119279; Email: mrhashemian@yahoo.com

Submitted: 20 January 2017

Approved: 10 March 2017

Published: 14 March 2017

Copyright: @ 2017 Hashemian SM, et al. This is an open access article distributed under the Creative Commons Attribution License, which permits unrestricted use, distribution, and reproduction in any medium, provided the original work is properly cited.

Keywords: Status epilepticus; Refractory status epilepticus; Nonconvulsive seizure; Pharmacotherapy algorithms
Review Article

\section{Critical Management of Status Epilepticus}

\author{
Farahnaz Fallahian ${ }^{1 *}$ and Seyed MohammadReza Hashemian ${ }^{2 *}$ \\ ${ }^{1}$ Rasoul Akram Hospital, Iran University of Medical Sciences, Tehran, Iran \\ ${ }^{2}$ Chronic Respiratory Disease Research Center (CRDRC), National Research Institute of \\ Tuberculosis and Lung Disease (NRITLD), Shahid Beheshti University of Medical Sciences \\ SBMU), Masih Daneshvari Hospital, Darabad St., Tehran, Iran
}

\section{ABSTRACT}

Seizure is clinical manifestation of sudden disruption of the normal electrical activity of cortical neurons. The brain electrical activity is periodically disturbed, alteration in neural cell integrity, increase in firing impulses and spread to adjacent normal neurons result in temporary brain dysfunction with alterations in consciousness, behavior or motor function. It may be triggered by illness, infection, stress, stroke, brain tumor, or the underlying cause may not completely understand. Status epilepticus (SE) is a medical emergency and requires prompt diagnosis and treatment. Treatment includes general support measures, drugs to suppress epileptic activity and relieving the underlying condition. Refractory SE requires admission to an intensive care unit (ICU) to allow adequate monitoring and support of respiratory, metabolic and hemodynamic functions and cerebral electrical activity. For SE treatment, benzodiazepines are the first line antiepileptic agents, and if benzodiazepines fail to control seizures, Phenytoin is usually indicated; Phenobarbital or Valproate may also be considered. For refractory SE, Propofol and Thiopental represent first line agents after careful assessment of potential risks. In refractory SE, general anesthesia may be required. There is currently no unique consensus for definite treatment option of RSE. In this review, the management protocol of seizure, assessment, monitoring, and different alternative therapy would be discussed.

\section{INTRODUCTION}

Status epilepticus (SE) is a life-threatening emergency that requires prompt treatment, including basic neuroresuscitation principles, antiepileptic drugs to stop the seizure and identification of etiology. A systematic treatment regimen, planned in advance, is needed, including one for refractory status epilepticus (RSE). The most important cause for SE varies with the age: Whereas febrile SE is the most common cause in children less than five years of age, trauma and infections are important in older children $[1,2]$. Severe hypoxic encephalopathy and inborn error of metabolism may present with SE in the newborn [1,3,4]. Low antiepileptic drug (AEDs) is an important precipitating factor in adult SE cases. In this review, mainly different medical pharmacological management protocols of seizure would be discussed.

\section{METHODS}

A review of literature was performed to summarize scientific reports on seizure, status epilepticus, refractory status epilepticus, nonconvulsive seizure, its definition, management, and pharmacotherapy from articles indexed in the PubMed database and Google for medical journals. Papers published during recent years (1980-2017) were searched by using the following key words: seizure, status epilepticus, refractory status epilepticus, nonconvulsive seizure, pharmacotherapy management.

\section{Definitions}

Status epilepticus (SE) is defined as continuous seizure activity of at least $30 \mathrm{~min}$ 
duration or intermittent seizure activity of at least $30 \mathrm{~min}$ duration during which consciousness is not regained.

Status epilepticus can be classified as generalized or partial seizures and either convulsive or non-convulsive in nature [5].

Treiman and colleagues [6,7] defined overt convulsive SE as two or more generalized convulsions without full recovery of consciousness between seizures, or continuous convulsive activity for more than 10 minutes. For practical purposes, SE should be considered if a seizure persists more than 5 minutes because very few single seizures last this long.

The operational definition is two or more seizures without full recovery of consciousness between seizures or recurrent epileptic seizures for more than 30 minutes $[8,9]$.

The overall mortality rate among adults with status epilepticus is approximately $20 \%[8,10]$. Status epilepticus should be stopped quickly, ideally within 30 minutes from the start of episode. Status epilepticus causes profound physiological changes that may result in severe systemic complications and may also damage or even kill cerebral neurons $[8,11]$.

Refractory status epilepticus (RSE) is usually defined as seizure activity that continues after first- and second-line therapy has failed [12].

Refractory status epilepticus can occur in $9 \%$ to $40 \%$ of the patients with status epilepticus [13,14]. Refractory status epilepticus has a mortality rate of up to $76 \%$ in elderly patients $[1,15]$. Nonconvulsive seizures (NCSz) and nonconvulsive status epilepticus (NCSE) are increasingly recognized as common occurrences in the ICU, where $8 \%-48 \%$ of comatose patients may have NCSz, depending on which patients are studied $[16,17]$. NCSz are electrographic seizures with little or no overt clinical manifestations, so electroencephalogram (EEG) is necessary for detection. NCSE occurs when NCSz are prolonged; a common definition is continuous or near-continuous electrographic seizures of at least 30 min duration $[16,18,19,20,21]$. In the pediatric population, especially in infants, NCSz are a more common occurrence (16), and younger age may be associated with a greater risk of NCSz [17].

\section{Etiologies}

The etiologies of seizures in critically ill patients are mentioned [7], as: Exacerbation of preexisting epilepsy, AED withdrawal, acute neurologic insult, cerebrovascular disease: infarct, hemorrhage (including subarachnoid, subdural, parenchymal, intraventricular), vasculitis, Infection: meningitis, encephalitis, brain abscess, head trauma, anoxia, brain tumors, demyelinating disorders, supratentorial neurosurgical procedure, acute systemic insult, electrolytes imbalances: hyponatremia, hypocalcemia, hypomagnesemia, hypophosphatemia (especially in alcoholics), hypoglycemia; hyperglycemia with hyperosmolar state; both can cause focal seizures as well, vitamin deficiency: pyridoxine, Illicit drug use, especially cocaine, toxins, hypertensive encephalopathy/eclampsia/posterior reversible, encephalopathy syndrome, hypotension, organ failure: renal, hepatic, multisystem illness, such as systemic lupus erythematosus, medications: side effects/toxicity, withdrawal (benzodiazepines, barbiturates), alcohol related, and systemic infection/sepsis.

\section{Assessment and management}

Perform patient assessment and record vital signs, level of consciousness, presenting signs and symptoms, and oxygen saturation. Initiate basic life support treatment measures, including supplemental oxygen. Repeat assessment, any changes including vital signs, level of consciousness, and perform continuous monitoring with 
ECG and monitor the effect of diazepam or lorazepam after each dose until and after that level of consciousness returns to normal. Also history of seizure, its features, and duration, total dose and time for anti-seizure drugs used, and resulting clinical effects should be written. General supportive measures begin with basic life support measures and adequate monitoring of vital signs and ECG. Assess and control airway. Monitor vital signs (including temperature) establish ECG and arterial pressure and pulse oximetry. Work up to define cause. Manage other medical problems. Give oxygen and obtain IV access [8].

Draw specimens for: Blood (Complete blood count, electrolytes, glucose, calcium, magnesium, phosphate, urea, creatinin, liver function tests, lactate, arterial blood gas analysis, troponin, creatine kinase (CPK), and drug concentration level if the patient is on anti-epileptic therapy.

Other work-up tests as: CSF for (Biochemistry, Cytology, Bacteriology, viral studies), urine (analysis, microscopy, myoglobin), toxicology screen (urine and blood), and brain CT Scan/MRI. EEG-It is now possible to record and monitor the continuous digital electroencephalogram (EEG) of many critically ill patients simultaneously. Continuous EEG monitoring (cEEG) provides dynamic information about brain function that permits early detection of changes in neurologic status, which is especially useful when the clinical examination is limited. cEEG is used to guide management of pharmacological coma for treatment of increased intracranial pressure. An emerging application for CEEG is to detect new or worsening brain ischemia in patients at high risk, especially those with subarachnoid hemorrhage. Improving quantitative EEG software is helping to make it feasible for cEEG (using full scalp coverage) to provide continuous information about changes in brain function in real time at the bedside and to alert clinicians to any acute brain event, including seizures, ischemia, increasing intracranial pressure, hemorrhage, and even systemic abnormalities affecting the brain, such as hypoxia, hypotension, acidosis, and others [15].

\section{Emergency treatment for status epilepticus}

Status epilepticus (SE) represents a major neurologic emergency, each year affecting 10 to 50/100,000 persons; in adults, its mortality rate ranges from 7 to 20\% [22-26]. Abou Khaled et al. [7] derived Status epilepticus management from Adult treatment protocol from Columbia University Comprehensive Epilepsy Center 2006 as:

Thiamine $100 \mathrm{mg}$ IV; $50 \mathrm{~mL}$ of D50 IV unless adequate glucose known.

Lorazepam $4 \mathrm{mg}$ (intravenously) IV over 2 mins; if still seizing, repeat 1 in 5 mins. If no rapid IV access, give diazepam $20 \mathrm{mg}$ per rectum (PR) or midazolam 10 mg intranasally, buccally or , intramuscularly (IMa) 10-20 If seizures persist, begin fosphenytoin $20 \mathrm{mg} / \mathrm{kg}$ IV at $150 \mathrm{mg} / \mathrm{min}$, with blood pressure and ECG monitoring. This step can be skipped initially, especially if proceeding to midazolam or propofol, or performed simultaneously with the next step; if done simultaneously, administration rate can be slowed.

IV Valproate is a reasonable alternative to fosphenytoin at this point as well (dosing below).

- 60 If seizures persist, give one of the following (intubation usually necessary except for valproate): continuous intravenous (CIV) midazolam: Load: $0.2 \mathrm{mg} /$ $\mathrm{kg}$; repeat $0.2-0.4 \mathrm{mg} / \mathrm{kg}$ boluses every 5 minutes until seizures stop, up to a maximum total loading dose of $2 \mathrm{mg} / \mathrm{kg}$. Initial CIV rate: $0.1 \mathrm{mg} / \mathrm{kg}$ per hr. CIV dose range: $0.05 \mathrm{mg} / \mathrm{kg}-2.9 \mathrm{mg} / \mathrm{kg}$ per $\mathrm{hr}$, titrate to EEG seizure control or burst suppression. If still seizing, add or switch to propofol or pentobarbital. Or: CIV propofol: Load: 1-2 mg/kg; repeat 1-2 mg/kg boluses every 3-5 minutes until seizures stop, up to maximum total loading dose of $10 \mathrm{mg} / \mathrm{kg}$. Initial cIV rate: 2 
$\mathrm{mg} / \mathrm{kg}$ per hr. CIV dose range: $1-15 \mathrm{mg} / \mathrm{kg}$ per hr titrate to EEG seizure control or burst suppression. If still seizing, add or switch to midazolam or pentobarbital. Avoid using $05 \mathrm{mg} / \mathrm{kg}$ per $\mathrm{hr}$ for multiple days to minimize risk of propofol infusion syndrome. Follow CPK, triglycerides, acid-base status closely.

- Or: IV valproate: $30-40 \mathrm{mg} / \mathrm{kg}$ over approximately 10 minutes. If still seizing, additional $20 \mathrm{mg} / \mathrm{kg}$ over approximately 5 minutes. If still seizing, add or switch to CIV midazolam or propofol.

- Or: IV Phenobarbital: $20 \mathrm{mg} / \mathrm{kg}$ IV at $50-100 \mathrm{mg}$ per min. If still seizing, add or switch to CIV midazolam, propofol, or pentobarbital.

- 60 minutes: CIV Pentobarbital. Load: $5 \mathrm{mg} / \mathrm{kg}$ at up to $50 \mathrm{mg}$ per min; repeat $5 \mathrm{mg} / \mathrm{kg}$ boluses until seizures stop. Initial CIV rate: $1 \mathrm{mg} / \mathrm{kg}$ per hr. CIV-dose range: $0.5-10 \mathrm{mg} / \mathrm{kg} \mathrm{mg} / \mathrm{kg}$ per hour; traditionally titrated to suppression burst on EEG but titrating to seizure suppression is reasonable as well.

Begin EEG monitoring as soon as possible if patient does not rapidly awaken, or if any CIV treatment is used.

The IV solution of diazepam can be given rectally if Diastat (Diazepam rectal Gel) is not available; the IV solution of midazolam can be given by any of these routes.

Benzodiazepines-Lorazepam has many advantages over other drugs. It can be given quickly and has a duration of antiseizure effect of 12 to 24 hours [7,27]. Leppik and colleagues $[7,27]$ compared lorazepam with diazepam for the treatment of SE in 78 subjects enrolled in a double-blind, randomized trial. These results, combined with the more recent and more definitive VA cooperative study, have led to intravenous lorazepam $(0.1 \mathrm{mg} / \mathrm{kg})$ becoming a clear drug of choice for initial treatment of SE [7].

Phenytoin (PHT), valproic acid (VPA), or levetiracetam (LEV) are commonly used as second-line treatment of status epilepticus (SE), but comparative studies are not available.

Our protocol to treat SE starts with intravenous benzodiazepines (clonazepam $0.015 \mathrm{mg} / \mathrm{kg}$ or lorazepam $0.1 \mathrm{mg} / \mathrm{kg}$ ), followed by a choice of PHT $20 \mathrm{mg} / \mathrm{kg}$, VPA $20 \mathrm{mg} / \mathrm{kg}$, or LEV $20 \mathrm{mg} / \mathrm{kg}$; all are relayed by maintenance dosages (typically, 300$400 \mathrm{mg}$ PHT, 1,000-2,500 mg VPA, or 1,000-3,000 mg LEV daily). The second-line treatment is typically administered within 1-30 min following benzodiazepines. Most of these drugs are given intravenously.

In conclusion, this study, which to the best of our knowledge represents the first comparison between PHT, VPA, and LEV in SE, suggests some caution in the use of LEV in this setting, pending a well-designed comparative trial [28].

In Bhagat [8] management protocol for status epilepticus, it is mentioned:

Start IV infusion (normal saline). If hypoglycemic or if blood glucose measurement is not available, give glucose for adults: $100 \mathrm{mg}$ thiamine IV followed by $50 \mathrm{ml}$ of $50 \%$ glucose, and for children: $2 \mathrm{ml} / \mathrm{kg}$ of $25 \%$ glucose.

- Benzodiazepines - Lorazepam: $0.1 \mathrm{mg} / \mathrm{kg} 1$ (max rate $2 \mathrm{mg} / \mathrm{kg}$ upto $4 \mathrm{mg}$ total dose).

- Diazepam: $0.2 \mathrm{mg} / \mathrm{kg}$ (max rate $5 \mathrm{mg} / \mathrm{kg}$ upto $20 \mathrm{mg}$

- Seizure persists: Phenytoin: $20 \mathrm{mg} / \mathrm{kg}$ (max: adults: $50 \mathrm{ml} / \mathrm{min}$; children: $1 \mathrm{mg} /$ $\mathrm{kg} / \mathrm{min}$ ).

- Fosphenytoin: $20 \mathrm{mg} / \mathrm{kg}$ Phenytoin equivalent (PE) (:150 mg/min). Monitor ECG / BP during infusion. 
- Seizure persists: Additional phenytoin (5-10 mg/kg) or fosphenytoin (5-10 mg/ kg PE).

- Seizure persists: Phenobarbital $20 \mathrm{mg} / \mathrm{kg}$ (max: $60 \mathrm{mg} / \mathrm{min}$ ). Expect respiratory depression / apnea, assist ventilation.

- If seizure continues: Anaesthesia with thiopentone sodium, midazolam or propofol.

Consider intubation and ventilation; Place arterial and central venous catheter, if indicated.

Use iv fluids and vasopressor for treating hypotension; Continue maintenance dose of phenytoin and phenobarbital.

Taper infusion at 12 hours to observe further seizure activity. If seizures recur, reinstate infusion in intervals of at least 12 hours.

In a study [29], the efficacy and tolerability of the treatment with Valproic acid (VPA) in patients with status epilepticus (SE) or acute repetitive seizures (ARS) comparing it with phenytoin (PHT) treatment was evaluated. In that study, the i.v. VPA patient group was treated with $30 \mathrm{mg}$ / $\mathrm{kg}$ given over 20 min diluted in $50 \mathrm{ml}$ of saline. The PHT patient group received PHT $18 \mathrm{mg} / \mathrm{kg}$ in $100 \mathrm{ml}$ of saline infused over 20 min; no maintenance dose was given. VPA i.v. seems to be effective and well tolerated in adult patients with SE or ARS. It concluded that the VPA i.v. is safe and effective for treating SE and ARS in adults. There is necessity for longer controlled double-blind studies which may provide more definitive results. Variable VPA dosing should also be studied in order to increase efficacy while trying to limit significant side effects.

Lawn et al. [30] introduces management options of status epilepticus as follows:

- First-line agents: The first-line drug of choice is intravenous lorazepam (LZP). Although direct comparison with diazepam (DZP) did not show any advantage in efficacy, other studies have suggested that LZP may be associated with a reduced rate of seizure recurrence [30,31].

Phenytoin should be administered immediately after LZP if seizures persist. The loading dose of PHT $(20 \mathrm{mg} / \mathrm{kg})$ should be infused in at least $100 \mathrm{ml}$ of $0.9 \%$ normal saline at a rate no greater than $50 \mathrm{mg} /$ minute. An average dose will, therefore, take approximately 30 minutes to administer. If there are continued seizures, a further $5-10 \mathrm{mg} / \mathrm{kg}$ of PHT should be given, and preparation for administration of a second-line agent should commence. The recommendation for further PHT has become a standard part of treatment algorithms in multiple reviews of SE [30]. The scientific basis for this is unclear. Fosphenytoin, a water-soluble prodrug of PHT, is likely to replace PHT although concerns regarding cost have limited its widespread use. However, fosPHT is safer and likely to be similarly effective [30].

- Second-line agents: If seizures remain uncontrolled or recur following at least two doses of benzodiazepines to a total of $0.1 \mathrm{mg} / \mathrm{kg}$ of LZP or $30 \mathrm{mg}$ DZP and intravenous PHT or fosPHT loading to a total of $30 \mathrm{mg} / \mathrm{kg}$ second line, agents should be used. Typically, by this stage, the patient will have been in established SE for over 20 minutes; and, although definitions in the literature vary, it is reasonable to consider this refractory status epilepticus. At this stage, the clinical manifestations have often evolved from overt tonic-clonic seizures to "subtle" or nonconvulsive SE where there may be minimal motor activity with intermittent low amplitude clonic movements often more limited in distribution. Preparation for the use of other agents and the possibility of intubation and mechanical ventilation should by this time be underway. In addition, arrangements for 
an EEG and/or continuous EEG monitoring should be initiated. At this point, a reassessment of the patient and the reasons for failure of initial therapy is warranted [30]. Intravenous PB has traditionally been utilized as a second line agent after failure of benzodiazepines and PHT [30,32].

It is suggested [30], that the second-line drug, after failure of initial therapy with LZP and PHT or fosPHT, should be midazolam. In addition, PB cannot be rapidly infused, thus incurring further delays. Those who remain in SE should be defined as refractory at this point rather than at an arbitrary time after seizure onset. This redefinition of the conceptual framework of SE justifies the earlier use of second-line agents. Midazolam in doses necessary to control refractory SE, particularly after initial therapy with benzodiazepines and, in some cases, failure of barbiturates, is likely to result in intubation becoming necessary. In addition, as clinical seizures may be difficult to assess in this setting, these patients should undergo continuous EEG monitoring to confirm electrographic cessation of seizures. Midazolam causes various EEG changes, most commonly drug-induced fast activity and generalized slowing and it is likely that seizure control will occur before a burst suppression pattern is seen [30], The recommended loading dose of midazolam is $10 \mathrm{mg}$ up to $0.2 \mathrm{mg} / \mathrm{kg}$ followed by an infusion at a rate 0.05 to $0.4 \mathrm{mg} / \mathrm{kg} /$ hour although higher doses may be necessary [30]. An alternative to midazolam is propofol, but experience with this agent in SE is also relatively limited.

- Third-line agents for seizure termination: If there is no response to high dose benzodiazepine infusion, the next step should involve an anesthetic barbiturate of which the best information and widest experience is available for pentobarbitone and thiopentone [30].

Pentobarbital has been traditionally advocated in North America as a third-line agent in refractory SE and guidelines have been established for its use [30,33-35]. The loading dose used in studies ranged between 5 and $20 \mathrm{mg} / \mathrm{kg}[30,33,34]$. It is suggested [30] an initial dose of $5 \mathrm{mg} / \mathrm{kg}$, increased as necessary to teminate clinical and electrographic seizure activity. This should be followed by an infusion rate of 0.5 to $5 \mathrm{mg} / \mathrm{kg} /$ hour although in one study seizures invariably recurred following an initial response to a bolus, at dose rates of less than $2.5 \mathrm{mg} / \mathrm{kg} / \mathrm{hour}$ [30].

Thiopentone, a parent drug of pentobarbital, has a similar profile to its metabolite although the elimination half-life is more prolonged with the possible advantage of reducing the rate of seizure recurrence on drug withdrawal $[30,36]$. The suggested dose is a bolus of 100 to $250 \mathrm{mg}$ with further $50 \mathrm{mg}$ boluses until seizures are controlled, followed by an infusion of $3-5 \mathrm{mg} / \mathrm{kg} / \mathrm{hour}[26,32]$. Cardiovascular intolerability is also frequently seen $[30,36]$. Both drugs are reported to predispose to infection related to adverse effects on immune function, which may compromise the care of a patient already at serious risk of ventilator associated pneumonia and other infectious complications [30,37]. During infusion, serum barbiturate levels can be monitored although therapeutic endpoints should be based primarily on clinical and electrographic response. Serum drug levels have been advocated to guide the rate of withdrawal but a practical approach with pentobarbital is to begin weaning 12 to 24 hours after the last clinical or electrographic seizure and taper the dose by 0.5 to $1.0 \mathrm{mg} / \mathrm{kg} /$ hour every four to six hours [30,38]. Barbiturate failure may be due to hemodynamic intolerance, recurrent seizures on attempted withdrawal, or failure of the drug itself.

Inhalational anesthetics may be considered under these circumstances. Experience with halothane, enflurane, and isoflurane has been reported [30]. There has also been considerable interest in the use of ketamine [30,39]. This short-acting N-methyl-Daspartate (NMDA) receptor antagonist does not cause respiratory depression and has outdone antiepileptic drugs in anecdotal cases [30]. 
Other options are [40,41]:

\section{- First line:}

Prehospital: midazolam 0.15-0.3 mg/kg IM (or intranasally or buccal). Alternatively diazepam $0.5 \mathrm{mg} / \mathrm{kg}$ rectally.

Inhospital: midazolam $0.1-0.3 \mathrm{mg} / \mathrm{kg}$, or diazepam $0.15 \mathrm{mg} / \mathrm{kg}$, or clonazepam 0.5 $-1 \mathrm{mg}$ or

lorazepam $0.1 \mathrm{mg} / \mathrm{kg}$ IV.

Follow with phenytoin $15-20 \mathrm{mg} / \mathrm{kg}$ IV diluted in saline at $50 \mathrm{mg} / \mathrm{min}$ with ECG monitoring and 0.22 micron filter. If available (not in Australia) give fosphenytoin 20 $\mathrm{mg} / \mathrm{kg}$ equivalence IV at $150 \mathrm{mg} / \mathrm{min}$, as does not contain propylene glycol so less incidence hypotension.

\section{- Second line:}

Phenobarbitone $10-20 \mathrm{mg} / \mathrm{kg}$ IV at $100 \mathrm{mg} / \mathrm{min}$ (popular in paediatrics). Use in ECG monitored area only.

\section{- Third line:}

Only in critical care area, with full monitoring ideally including EEG. No good randomised trials comparing the different drugs.

More midazolam; or phenytoin to total $30 \mathrm{mg} / \mathrm{kg}$.

Thiopentone - may require IPPV and vasopressor support.

Propofol 3-5 mg/kg, then infusion at 30-100 $\mu \mathrm{g} / \mathrm{kg} / \mathrm{min}$; lignocaine or inhaled anaesthetic such as isoflurane, etc.

Valproate IV, no evidence of superiority, but ease of swapping to oral form.

Levetiracetam (Keppra) PO and IV. Sparse data.

Airway management should prevent aspiration of gastric contents. Neuromuscular blocking drugs will be required to secure the airway but should not be needed after that. If they are required, continuous EEG monitoring must be used to allow monitoring of seizure activity.

Other management includes monitoring of electrocardiography, and fluid resuscitation to maintain arterial pressure at normal levels ensuring adequate cerebral perfusion pressure. Hypoglycaemia should be treated with $50 \%$ glucose 50 $\mathrm{ml}$. Mortality is $\sim 25 \%[5,42,43]$.

Lorazepam in a dose of $0.1 \mathrm{mg} / \mathrm{kg}$ is recommended as first-line therapy for the control of status epilepticus. Based on this information, lorazepam should replace diazepam in hospital code carts and "orange bags," it should be stored in light-proof containers, and should be restocked every 4 to 6 months [44,45].

Many authorities recommend phenytoin, $20 \mathrm{mg} / \mathrm{kg}$ (or fosphenytoin), following the administration of lorazepam. While there are no data that demonstrate that phenytoin increases the response rate following the use of lorazepam, this agent may prevent recurrent seizures and is recommended in patients without a rapidly reversible process (eg, the effect of subtherapeutic antiepileptic drug concentrations) [44-46].

\section{Nonconvulsive status epilepticus}

Occurring in about $8 \%$ of all comatose patients without clinical signs of seizure 
activity [42,45], and persisting in $14 \%$ of patients after generalized convulsive status epilepticus [44,47], and constitutes approximately 20 to $25 \%$ of status epilepticus cases $[44,48,49]$. Based on this information, it has been suggested that comatose patients with nonconvulsive status epilepticus and nonconvulsive status epilepticus following generalized convulsive status epilepticus be treated aggressively as outlined above for refractory convulsive status epilepticus [44]. Patients who have generalized seizures that continue for more than 5 min should be considered to have status epilepticus and should be treated with a single IV dose of lorazepam $(0.1 \mathrm{mg} / \mathrm{kg})$. Patients who continue to have clinical or EEG evidence of seizure activity after receiving treatment with lorazepam should be considered to have refractory status epilepticus and should treated with a continuous infusion of propofol or midazolam [44].

\section{Refractory status epilepticus}

In a study, concluded that in their series, PRO administered concomitantly with CZP and PHT was effective in controlling most of RSE episodes by inducing burst suppression on CEEG. PRO was well tolerated, and PRO infusion syndrome was not seen. Furthermore, data suggest that the use of PRO may result in a shorter duration of treatment. However, a randomized controlled study is required to compare directly the effectiveness of barbiturates and PRO in the treatment of RSE [50].

Management of Refractory Status Epilepticus [1]:

- $\quad$ Place EEG monitor and central lines

- Monitor blood pressure

- $\quad$ Keep ventilatory support ready

- $\quad$ Midazolam $0.15 \mathrm{mg} / \mathrm{kg}$ stat, infusion $0.75-18 \mathrm{ug} / \mathrm{kg} / \mathrm{minute}$ or

- Diazepam $0.3 \mathrm{mg} / \mathrm{kg}$ stat, infusion $0.01-0.04 \mathrm{mg} / \mathrm{kg} / \mathrm{min}$ or

- With ventilatory support

- Propofol $1-3 \mathrm{mg} / \mathrm{kg}$ stat, infusion $2-10 \mathrm{mg} / \mathrm{kg} / \mathrm{hr}$ or

- Pentobarbital 5-15 mg/kg stat, infusion $0.5-5 \mathrm{mg} / \mathrm{kg} / \mathrm{hr}$ or

- Thiopental infusion 3-4 mg/kg stat, infusion $1-10 \mathrm{mg} / \mathrm{kg} / \mathrm{min}$

A variety of agents has been recommended for the treatment of refractory status epilepticus, including midazolam, propofol, high-dose thiopentone or pentobarbital, IV valproate, topiramate, tiagabine, ketamine, isoflurane, and IV lidocaine. Treatment guidelines are difficult to formulate as refractory status epilepticus has not been studied in a prospective clinical trial. Currently, however, a continuous IV infusion of midazolam or propofol together with continuous EEG monitoring is the preferred mode of treatment $[44,51,52]$.

If it is needed for intubation,rapid sequence intubation is preferred. Use of Rocuronium $1 \mathrm{mg} / \mathrm{kg}+/$ - propofol or etomidate is recommended [44].

Midazolam is given as a loading dose of $0.2 \mathrm{mg} / \mathrm{kg}$, followed by an infusion of 0.1 to $2.0 \mathrm{mg} / \mathrm{kg} / \mathrm{h}$ titrated to produce seizure suppression by continuous EEG monitoring.

Propofol is an IV alkylphenol (2,6-di-isopropylphenol), which has been used extensively for the induction and maintenance of anesthesia and for sedation in the ICU. Propofol is a global CNS depressant. It directly activates the GABA receptor $[44,53,54]$. In addition, propofol inhibits the NMDA receptor, modulates calcium influx through slow calcium ion channels, and has antioxidant activity [44,55]. The most severe complication associated with propofol is the "propofol infusion syndrome," a very rare 
complication reported predominantly in pediatric patients and associated with highdose propofol infusion [44,56-58]. The propofol infusion syndrome is characterized by severe metabolic acidosis, rhabdomyolysis, and cardiovascular collapse frequently leading to death $[44,57,58]$.

High-dose barbiturate therapy is associated with hemodynamic instability and immune paresis. Due to their side effects, therapy with barbiturates is reserved for those patients who do not respond to midazolam or propofol. Pentobarbital therapy, in a dose of 10 to $15 \mathrm{mg} / \mathrm{kg} / \mathrm{h}$ followed by a dose of 0.5 to $1.0 \mathrm{mg} / \mathrm{kg} / \mathrm{h}$, is recommended [44].

Management of RSE requires coma induction with potent anesthetics under continuous EEG (cEEG) monitoring, implying mechanical ventilation in an intensive care unit (ICU) setting. The aim of treatment is to terminate SE and to prevent late SE-associated complications, including hyperthermia, hypotension, hypoglycemia, rhabdomyolysis, pulmonary edema, cerebral edema, and failure of cerebral autoregulation [50,59,60]. Barbiturates [pentobarbital (PTB) and thiopental (THP)] are the anesthetics most commonly used to induce coma in this setting, especially in Europe $[50,61,62]$.

A study [61], concluded: The optimal pharmacologic treatment for early convulsive status epilepticus is unclear. In adults with convulsive status epilepticus, intramuscular midazolam, intravenous lorazepam, intravenous diazepam and intravenous phenobarbital are established as efficacious as initial therapy (Level A). Intramuscular midazolam has superior effectiveness compared to intravenous lorazepam in adults with convulsive status epilepticus without established intravenous access (Level A) [63].

Other new drugs- Recently, three new drugs have been introduced for the medication. The retigabine is a carbamic derivate. The lacosamide is a functionalized amino acid, and selectively enhances voltage-gated sodium channel slow inactivation. The eslicarbazepine acetate is a new member of the dibenzazepine family, and blocks the fast inactivated voltage-gated sodium channel. These novel anticonvulsants appear to be a safe and effective addition to the armamentarium for the treatment of patients with refractory epilepsy. However, it must take some new approaches into consideration, in the therapeutic algorithm [64]. Tiagabine is one of the newer antiepileptic drugs. According to a review, Tiagabine reduces seizure frequency but is associated with some adverse effects when used as an add-on treatment for people with drug-resistant localization-related seizures [65].

\section{CONCLUSION}

Epilepsy is not a singular disease, but a variety of disorders. It is affects up to $0.5 \%$ of the population and up to $15-20 \%$ of these patients have refractory epilepsy. As the treatment pathway progresses, the expertise of an anaesthetist/intensivist should be sought [66]. An individual treatment pathway should be formulated for people who have recurrent convulsive status epilepticus [66]. The possibility of having seizures should be discussed and information on epilepsy should be provided before seizures occur, for people at high risk of developing seizures (such as after severe brain injury), people with a learning disability, or people who have a strong family history of epilepsy [66]. Quantitative EEG (qEEG) qEEG-based tools, such as Bispectral Index [67], patient state index [68], and Narcotrend [69] have been in use in operating rooms and ICUs for more than a decade to monitor depth of sedation. Although these single purpose devices use proprietary algorithms, evaluation of the raw cEEG or qEEG measures can also provide information about arousal in the paralyzed patient [70].

Treatment option another study [71], consists of: 
All antiepileptic drugs (AEDs) commonly used as first-line treatment in SE are benzodiazepines.

Early Status Epilepticus- Stage I: Lorazepam (Intravenous (IV) and Intranasal (IN), Diazepam (IV, Rectal), Clonazepam (IV), Midazolam (IV), Intramuscular (IM), Intranasal, Buccal.

Established Status epilepticus (SE) designates continuous seizure activity with convulsions or intermittent seizures without regaining consciousness between the seizures.

Established Status Epilepticus- Stage II: Phenytoin/Fosphenytoin (IV), Valproic Acid (IV), Levetiracetam (IV), Phenobarbital (IV, IM).

For Refractory Status Epilepticus- Stage III: Midazolam (Continuous IV Infusion), Propofol, Thiopental, Pentobarbital, Isoflurane (Inhalation), Etomidate (IV).

When treatment with an IV anesthetic for more than $24 \mathrm{~h}$ is not successful in controlling SE, the condition can be termed super-refractory SE or malignant SE [71,72].

For Super-Refractory Status Epilepticus- Stage IV: Recommendations are based exclusively on small case series, including several treatment options, such as ketamine, corticosteroids, magnesium, IV immunoglobulin, a ketogenic diet, and neurostimulation, and in lesional cases, also surgery. It is advised to establish a protocol-driven treatment approach Ketamine (IV infusion), Magnesium (IV), Topiramate (Enteral), Immunotherapy: Corticosteroids, IV Immunoglobulins, Plasma Exchange [71].

Other Drugs Used in Status Epilepticus: Lacosamide (IV), Paraldehyde (IM, Rectal), Lidocaine (I), Chlormethiazole (IV), Carbamazepine (Rectal, IV) [71].

Another guideline [63], mentioned that, the clinical algorithm/guideline is designed to assist clinicians by providing an analytical framework for evaluating and treating patients with status epilepticus. It is not intended to establish a community standard of care, replace a clinician's medical judgment, or establish a protocol for all patients. The clinical conditions contemplated by this algorithm/guideline will not fit or work with all patients. Approaches not covered in this algorithm/guideline may be appropriate. In that study, Intramuscular midazolam $(10 \mathrm{mg}>40 \mathrm{~kg}, 5 \mathrm{mg} 13-40 \mathrm{~kg}$, single dose, level A), is one of proposed treatment for status epilepticus in 5-20 minutes initial therapy phase.

It is stated in another study [73], that: Status epilepticus (SE) requires not only urgent symptomatic treatment with antiepileptic drugs but also rapid identification and treatment of its cause. This narrative review summarizes the most important advances in classification and treatment of SE. Treatment options in refractory SE are intravenous anaesthetics; ketamine, magnesium, steroids and other drugs have been used in super-refractory SE with variable outcomes [73]. Over the past 25 years major advances in definition, classification and understanding of its mechanisms have been achieved. Despite this up to $40 \%$ of patients in early status cannot be controlled with first line drugs. The treatment of super-refractory status is still an almost evidence free zone [73]. Management of refractory status epilepticus and super-refractory status epilepticus remains mostly non-evidence-based. Increasing recognition of a possible autoimmune aetiology has led to the use of immune-modulation in superrefractory status epilepticus. Ketamine is also increasingly used in this challenging condition. There are also reports of potential use of a ketogenic diet and magnesium [74]. Surgery for epilepsy remains, arguably, the most underutilized of all acceptable medical interventions, and the reasons for this are unclear [75]. 
Polytherapy may be necessary for the treatment of concomitant disease. Physicians prescribing AEDs to patients with epilepsy must, therefore, be aware of the potential for drug interactions and the effects (pharmacokinetic and pharmacodynamic) that can occur both during combination therapy and on drug discontinuation. Although pharmacokinetic interactions are numerous and well described, pharmacodynamic interactions are few and usually concluded by default. Perhaps the most clinically significant pharmacodynamic interaction is that of lamotrigine (LTG) and valproic acid (VPA); these drugs exhibit synergistic efficacy when coadministered in patients with refractory partial and generalised seizures. Hepatic metabolism is often the target for pharmacokinetic drug interactions, and enzyme-inducing drugs such as phenytoin (PHT), phenobarbitone (PB), and carbamazepine (CBZ) will readily enhance the metabolism of other AEDs [e.g., LTG, topiramate (TPM), and tiagabine (TGB)] [22].

Current anti-seizure medications, especially valproic acid, have some neuroprotective potential. Similarly, there is some hope of neuroprotection with newer anti-seizure drugs such as retigabine and levetiracetam. Several studies have demonstrated that $\beta$-estradiol has indeed potency to protect neurons from seizureinduced damage. Additional studies are required to determine exact mechanisms of $\beta$-estradiol and SERMs in seizure-induced neuroprotection for truly individualized and effective therapy [23].

Some of the side and beneficial effects of AEDs are mediated via the influence on mitochondria. In clinical practice mitochondrial epilepsy should be initially treated with AEDs with low mitochondrion-toxic potential [24]. There is a perception that the elderly are generally more susceptible to the adverse effects of Antiepileptic drugs (AEDs) than younger adults, although there are few data to validate this claim. Dose-dependent and idiosyncratic reactions may be more frequent. Common adverse effects of valproic acid (VPA) include gastrointestinal symptoms and tremor [25]. Antiepileptics such as Phenytoin was found to cause Toxic epidermal necrolysis (TEN) [26].

Patient education and home management of seizures is important to reduce the morbidity and mortality associated with SE. Patients should become informed about the medicines, its side effects, to take the medicines regularly, to tell the drug name to doctor if another medical condition occurred. Selection of second and third line therapy, dose of continuous infusion therapy, assessment of statistics for appropriate protocol adherence and its response in emergency and critical care units and home follow-up needs more investigation and trials to transform to unique protocol.

Clinical trials is needed to compare the best option for age, heterogeneous etiologies of seizure type, adverse effects of disease and safety profiles of treatment, effective dose, tolerability, outcome analysis, genetic variations in drug response, pharmacogenetics and pharmacogenomics, drug interactions, associated conditions with poor outcomes and functional impairments. Also, studies necessary to assess when should be considered for monotherapy, or for other add-on drugs, the best option for post-stroke, subdural hematoma, intracranial hemorrhage, after head trauma, electroconvulsive therapy (ECT), and neuroprotective strategies trials.

\section{REFERENCES}

1. Behera MK, Rana KS, Kanitkar M, Adhikari KM. Status Epilepticus in Children. Med J Armed Forces India. 2005; 61: 174-178. Ref.: https://goo.gl/alP7Fp

2. Singhi S, Singhi P, Dass R. Status epilepticus: Emergency management. Indian J Pediatr. 2003; 70; 1: S1-22. Ref.: https://goo.gl//lvnEc

3. Gulati S, Vasudevan A. Status epilepticus. In: Suraj Gupte, editor. Text Book of Pediatric Emergencies. New Delhi: Peepee Publishers and Distributors. 2004; 134-141. 
4. Chin RF, Verhulst L, Neville BG, Peters MJ, Scott RC. Inappropriate emergency management of Status epilepticus in children contributes a need for intensive care. J Neurol Neurosurg Psychiatry. 2004; 75: 1584-1588. Ref.: https://goo.gl/1Qqz7U

5. Gratrix AP, Simon M Enright. Epilepsy in anaesthesia and intensive care. Contin Educ Anaesth Crit Care Pain. 2005; 5: 118-121. Ref.: https://goo.gl/6pLQch

6. Treiman DM, Meyers PD, Walton NY, Collins JF, Colling C, et al. A comparison of four treatments for generalized convulsive status epilepticus. Veterans Affairs Status Epilepticus Cooperative Study Group. N Engl J Med. 1998; 339: 792-798. Ref.: https://goo.gl/6qo4Ho

7. Abou Khaled KJ, Hirsch LJ. Updates in the management of seizures and status epilepticus in critically ill patients. Neurol Clin. 2008; 26: 385-408. Ref.: https://goo.gl/DBKrXc

8. Bhagat $\mathrm{H}$, Dash $\mathrm{HH}$. Anaesthesiologist's role in the management of an epileptic patient. Indian J. Anaesth. 2006; 50: 20-26. Ref.: https://goo.gl/17uwFS

9. Treiman DM. Status epilepticus. In: Laidlaw J, Richens A, Chadwick D, editors: A textbook of epilepsy. New York, Churchill Livingstone 1993: 205.

10. Lowenstein DH, Alldredge BK. Status epilepticus. N Eng J Med. 1998; 338: 970-976. Ref.: https://goo.gl/gRA6bo

11. Treiman DM. Treatment of status epilepticus. In: Engel Jr J, Pedley TA editors: Epilepsy: A comprehensive textbook. Philadelphia: Lippincott-Raven. 1997; 1317-1323.

12. Shorvon S. Status Epilepticus: Its Clinical Features and Treatment in Children and Adults. Cambridge, England: Cambridge University Press. 1994; 201. Ref.: https://goo.gl/b73xeA

13. Claassen J, Hirsch LJ, Emerson RG, Mayer SA. Treatment of refractory status epilepticus with pentobarbital, propofol, midazolam: a systemic review. Epilepsia. 2002; 43: 146-153. Ref.: https://goo.gl//k4cnBr

14. Mayer SA, Claassen J, Lokin J, Mendesohn F, Dennis LJ, et al. Refractory status epilepticus: frequency, risk factors, and impact on outcome. Arch Neurol. 2002; 59: 205-210. Ref. https://goo.gl/PwpVS6

15. Logroscino G, Hesdorffer DC, Cascino G, Hauser WA, Coeytaux A, et al. Longterm mortality after a first episode of status epilepticus. Neurology. 2002; 58: 537-541. Ref.: https://goo.gl/qcGTFZ

16. Friedman D, Claassen J, Hirsch LJ. Continuous Electroencephalogram Monitoring in the Intensive Care Unit. Anesth Analg. 2009; 109: 506-523. Ref.: https://goo.gl/VTY7Es

17. Claassen J, Mayer SA, Kowalski RG, Emerson RG, Hirsch LJ. Detection of electrographic seizures with continuous EEG monitoring in critically ill patients. Neurology. 2004; 62: 1743-1748. Ref.: https://goo.gl/5SyQ4w

18. DeLorenzo RJ, Waterhouse EJ, Towne AR, Boggs JG, Ko D, et al. Persistent nonconvulsive status epilepticus after the control of convulsive status epilepticus. Epilepsia. 1998; 39: 833-840. Ref.: https://goo.gl/Jt4VnZ

19. Walker M, Cross H, Smith S, Young C, Aicardi J, et al. Nonconvulsive status epilepticus: Epilepsy Research Foundation workshop reports. Epileptic Disord. 2005; 7: 253-296. Ref.: https://goo.gl/cJh2AP

20. Jordan KG. Nonconvulsive status epilepticus in acute brain injury. J Clin Neurophysiol. 1999; 16: 332-340. Ref.: https://goo.gl/cxjNA6

21. Young GB, Jordan KG, Doig GS. An assessment of nonconvulsive seizures in the intensive care unit using continuous EEG monitoring: an investigation of variables associated with mortality. Neurology. 1996; 47: 83-89. Ref.: https://goo.gl/0llLtY

22. Patsalos PN, Fröscher W, Pisani F, van Rijn CM. The importance of drug interactions in epilepsy therapy. Epilepsia. 2002; 43: 365-385. Ref.: https://goo.gl/aDaerp

23. Velisek L, Nebieridze N, Chachua T, Veliskova J. Anti-seizure medications and estradiol for neuroprotection in epilepsy: the 2013 update. Recent Pat CNS Drug Discov. 2013; 8: 24-41. Ref.: https://goo.gl/mBfLfg

24. Finsterer J. Toxicity of Antiepileptic Drugs to Mitochondria. Handb Exp Pharmacol. 2016 Sep 3. Ref.: https://goo.gl/zYnUOz

25. Stephen LJ. Drug treatment of epilepsy in elderly people: focus on valproic Acid. Drugs Aging. 2003; 20: 141-152. Ref.: https://goo.gl/etP0Qm 
26. Al-Quteimat OM. Phenytoin-induced toxic epidermal necrolysis: Review and recommendations. J Pharmacol Pharmacother. 2016; 7: 127-132. Ref.: https://goo.gl/PuuUXy

27. Leppik IE, Derivan AT, Homan RW, Walker J, Ramsay RE, et al. Double-blind study of lorazepam and diazepam in status epilepticus. JAMA. 1983; 249: 1452-1454. Ref.: https://goo.gl/jBM1rk

28. Alvarez V, Januel JM, Burnand B, Rossetti AO. Second-line status epilepticus treatment: comparison of phenytoin, valproate, and levetiracetam. Epilepsia. 2011; 52: 1292-1296. Ref.: https://goo.gl/73Vv09

29. Gilad R, Izkovitz N, Dabby R, Rapoport A, Sadeh M, et al. Treatment of status epilepticus and acute repetitive seizures with i.v. valproic acid vs phenytoin. Acta Neurol Scand. 2008; 118: 296-300. Ref.: https://goo.gl/z69fP4

30. Lawn ND, Wijdicks EFM. Status epilepticus: A critical review of management Options. Can J Neurol Sci. 2002; 7: 47-59. Ref.: https://goo.gl/znppHj

31. Alldredge BK, Gelb AM, Isaacs SM, Corry MD, Allen F, et al. A comparison of lorazepam, diazepam, and placebo for the treatment of out-of-hospital status epilepticus. N Engl J Med. 2001; 345: 631637. Ref.: https://goo.gl/55M3QS

32. WE Dodson, RJ DeLorenzo, TA Pedley. Working Group on Status Epilepticus. Treatment of convulsive status epilepticus. Recommendations of the Epilepsy Foundation of America's working group on status epilepticus. JAMA. 1993; 270: 854-859.

33. Osorio I, Reed RC. Treatment of refractory generalized tonic-clonic status epilepticus with pentobarbital anesthesia after high-dose phenytoin. Epilepsia. 1989; 30: 464-471. Ref.: https://goo.gl/iAGv7j

34. Lowenstein DH, Aminoff MJ, Simon RP. Barbiturate anesthesia in the treatment of status epilepticus: clinical experience with 14 patients. Neurology 1988; 38: 395-400. Ref.: https://goo.gl/NNAL1i

35. Yaffe K, Lowenstein DH. Prognostic factors of pentobarbital therapy for refractory generalized status epilepticus. Neurology. 1993; 43: 895-900. Ref.: https://goo.gl/IOyyGC

36. Shorvon S. Status epilepticus: its clinical features and treatment in children and adults. Cambridge, England: Cambridge University Press, 1994. Ref.: https://goo.gl/gnqT9X

37. Moudgill GC. Update on anaesthesia and the immune response. Can Anaesth Soc J. 1986; 33 : S54-S60. Ref.: https://goo.gl/eoS62l

38. Kinoshita H, Nakagawa E, Iwasaki Y, Hanaoka S, Sugai K. Pentobarbital therapy for status epilepticus in children: timing of tapering. Pediatr Neurol. 1995; 13: 164-168. Ref.: https://goo.gl/tIMD1m

39. Sheth RD, Gidal BE. Refractory status epilepticus: response to ketamine. Neurology. 1998; 51: 17651766. Ref.: https://goo.gl/6PaOFq

40. Lifeinthefastlane.com http://lifeinthefastlane.com/2010/10/ebm-status-epilepticus/Status Epilepticus EBM Review October 31, 2010 By Mike Cadogan. Ref.: https://goo.gl/CNwIY5

41. Costello DJ, Cole AJ. Treatment of acute seizures and status epilepticus. J Intensive Care Med. 2007; 22: 319-47. Ref.: https://goo.gl/CpF2aE

42. Chapman MG, Smith M, Hirsch NP. Status epilepticus. Anaesthesia. 2001; 56: 648-659. Ref.: https://goo.gl/Blv50K

43. Treiman DM, Convulsive status epilepticus. Curr Treat Options Neurol. 1999; 1: 359-369. Ref.: https://goo.gl/euvGNh

44. Marik PE, Varon J. The Management of Status Epilepticus. Chest. 2004; 126: 582-591. Ref.: https://goo.gl/wcMrBW

45. Alldredge BK, Gelb AM, Isaacs SM, Corry MD, Allen F, et al. A comparison of lorazepam, diazepam, and placebo for the treatment of out-of-hospital status epilepticus. N Engl J Med. 2001; 345: 631637. Ref.: https://goo.gl/HUhXa2

46. Lowenstein DH, Alldredge BK. Status epilepticus. N Engl J Med. 1998; 338: 970-976. Ref.: https://goo.gl/m830bh

47. Towne AR, Waterhouse EJ, Boggs JG, Garnett LK, Brown AJ, et al. Prevalence of nonconvulsive status epilepticus in comatose patients. Neurology. 2000; 54: 340-345. Ref.: https://goo.gl/5qFVBG

48. Celesia G. Modern concepts of status epilepticus. JAMA. 1976; 235:1571-1574. Ref.: https://goo.gl/SsyGCi 
49. Dunne JW, Summers QA, Stewart-Wynne EG. Non-convulsive status epilepticus: a prospective study in an adult general hospital. Q J Med. 1987; 62: 117-126. Ref.: https://goo.gl/eFYQGB

50. RossettiAO,ReichhartMD,SchallerMD,DesplandPA,BogousslavskyJ.PropofolTreatment of Refractory Status Epilepticus: A Study of 31 Episodes. Epilepsia. 2004; 45: 757-763. Ref.: https://goo.gl/nr5gxu

51. Mayer SA, Claassen J, Lokin J, Mendelsohn F, Dennis LJ, et al. Refractory status epilepticus: frequency, risk factors, and impact on outcome. Arch Neurol. 2002; 59: 205-210. Ref.: https://goo.gl/90vWyo

52. Claassen J, Hirsch LJ, Emerson RG, Mayer SA. Treatment of refractory status epilepticus with pentobarbital, propofol, or midazolam: a systematic review. Epilepsia. 2002; 43: 146-153. Ref.: https://goo.gl/efFyzH

53. Smith I, White PF, Nathanson M, Gouldson R. Propofol: an update on its clinical use. Anesthesiology. 1994; 81: 1005-1043. Ref.: https://goo.gl/K3jOIX

54. Hara M, Kai Y, Ikemoto Y. Propofol activates GABAA receptor-chloride ionophore complex in dissociated hippocampal pyramidal neurons of the rat. Anesthesiology. 1993; 79: 781-788. Ref.: https://goo.gl/uc8vMM

55. Orser BA, Bertlik M, Wang LY, JF MacDonald. Inhibition by propofol (2,6 di-isopropylphenol) of the $\mathrm{N}$-methyl-D-aspartate subtype of glutamate receptor in cultured hippocampal neurones. $\mathrm{Br} \mathrm{J}$ Pharmacol. 1995; 116: 1761-1768. Ref.: https://goo.gl/adVxBm

56. Vasile B, Rasulo F, Candiani A, Latronico N. The pathophysiology of propofol infusion syndrome: a simple name for a complex syndrome. Intensive Care Med. 2003; 29: 1417-1425. Ref.: https://goo.gl/LZWeOl

57. Parke TJ, Stevens JE, Rice AS, CL Greenaway, RJ Bray, et al. Metabolic acidosis and fatal myocardial failure after propofol infusion in children: five case reports. BMJ. 1992; 305: 613-616. Ref.: https://goo.gl/8g46d6

58. Kang TM. Propofol infusion syndrome in critically ill patients. Ann Pharmacother. 2002; 36: 1453 1456. Ref.: https://goo.gl/xzz2oz

59. Shorvon S. The management of status epilepticus. J Neurol Neurosurg Psychiatry. 2001; 70: 22-27. Ref.: https://goo.gl/JJEYZe

60. Bassin S, Smith TL, Bleck TP. Clinical review: status epilepticus. Crit Care. 2002; 6: 137-142. Ref.: https://goo.gl/06dYCg

61. Coeytaux A, Jallon P, Galobardes B, Morabia A. Incidence of status epilepticus in French-speaking Switzerland (EPISTAR). Neurology. 2000; 55: 693-697. Ref.: https://goo.gl/silOFp

62. Holtkamp M, Masuhr F, Harms L, K Einhaupl, H Meierkord, et al. The management of refractory generalised convulsive and complex partial status epilepticus in three European countries: a survey among epileptologists and critical care neurologists. J Neurol Neurosurg Psychiatry. 2003; 74: 10951099. Ref.: https://goo.gl/CqmT5

63. Glauser T, Shinnar S, Gloss D, Alldredge B, Arya R, et at. Evidence-Based Guideline: Treatment of Convulsive Status Epilepticus in Children and Adults: Report of the Guideline Committee of the American Epilepsy Society. Epilepsy Curr. 2016; 16: 48-61. Ref.: https://goo.gl/W2kUUt

64. Szupera Z. [New antiepileptic drugs, and therapeutic considerations]. Ideggyogy Sz. 2011 Sep 30; 64(9-10):329-32.

65. Pulman J, Hutton JL, Marson AG. Tiagabine add-on for drug-resistant partial epilepsy. Cochrane Database Syst Rev. 2012; 5: CD001908. Ref.: https://goo.gl/6g1CHt

66. Stokes T, Shaw EJ, Juarez-Garcia A, Camosso-Stefinovic J, Baker R. Clinical Guidelines and Evidence Review for the Epilepsies: diagnosis and management in adults and children in primary and secondary care London: Royal College of General National Collaborating Centre for Primary Care. 2004.

67. Simmons LE, Riker RR, Prato BS, Fraser GL. Assessing sedation during intensive care unit mechanical ventilation with the Bispectral Index and the Sedation-Agitation Scale. Crit Care Med. 1999; 27: 1499504. Ref.: https://goo.gl/UelxDH

68. Prichep LS, Gugino LD, John ER, Chabot RJ, Howard B, et al. The Patient State Index as an indicator of the level of hypnosis under general anaesthesia. Br J Anaesth. 2004; 92: 393-399. Ref.: https://goo.gl/FbkbtR 
69. Bauerle K, Greim CA, Schroth M, Geisselbrecht M, Kobler A, et al. Prediction of depth of sedation and anesthesia by the Narcotrend EEG monitor. Br J Anaesth. 2004; 92: 841-845. Ref.: https://goo.gl/xMhEfF

70. Roustan JP, Valette S, Aubas P, Rondouin G, Capdevila X. Can electroencephalographic analysis be used to determine sedation levels in critically ill patients? Anesth Analg. 2005; 101: 1141-1151. Ref.: https://goo.gl/7i6uFa

71. Trinka E, Höfler J, Leitinger M, Brigo F. Pharmacotherapy for Status Epilepticus. Drugs. 2015; 75: 1499-1521. Ref.: https://goo.gl/cwlhin

72. Shorvon S, Ferlisi M. The treatment of super-refractory status epilepticus: a critical review of available therapies and a clinical treatment protocol. Brain. 2011; 134: 2802-2818. Ref.: https://goo.gl/QyhDb9

73. Trinka E, Kälviäinen R. 25 years of advances in definition, classification and treatment of status epilepticus. Seizure. 2017; 44: 65-73. Ref.: https://goo.gl/lvJo7N

74. Fung EL, Fung BB; Subcommittee on the Consensus Statement of the Hong Kong Epilepsy Society Review and update of the Hong Kong Epilepsy Guideline on status epilepticus. Hong Kong Med J. 2017; 23: 67-73. Ref.: https://goo.gl/8CPVHF

75. Engel J Jr. What can we do for people with drug-resistant epilepsy? The 2016 Wartenberg Lecture. Neurology. 2016; 87: 2483-2489. Ref.: https://goo.gl/dDvOHt

76. DeLorenzo RJ, Waterhouse EJ, Towne AR, Boggs JG, Ko D, et al. Persistent nonconvulsive status epilepticus after the control of convulsive status epilepticus. Epilepsia. 1998; 39: 833-840. Ref.: https://goo.gl/QMPAZ0 